\title{
GRAMÁTICAS OU CONJUNTOS ORGÂNICOS DE TRAÇOS TRANSDUTIVOS E ALAGMÁTICOS: CAMINHOS PARA O LETRAMENTO-CARTOGRAFIA
}

\section{GRAMMARS OR ORGANIC SETS OF TRANSDUCTIVE AND ALAGMATIC TRACES: PATHS TO LETTERING- CARTOGRAPHY}

Luiz Roberto Peel Furtado de Oliveira*

Rosélia Sousa Silva**

Priscila Venâncio Costa ${ }^{* * * *}$

\begin{abstract}
Resumo: Esta produção reflete acerca das práticas reducionistas do ensino de gramáticas e das outras formas de trabalho possíveis de serem trilhadas, com uso da transdução como forma de raciocínio, rumo à vivência de leitura e de estudos mais sérios e profícuos que ampliem horizontes e efetivem individuações. Deleuze e Guattari são nossas óticas filosóficas principais; Neves, Faraco e outros serviramnos com suas inquietações distintas no território do ensino de língua; textos de Gabriel Magalhães fundamentam nossas reflexões e análises, que preocupam com a necessidade de vivenciar os procedimentos cartográficos, os sabores da aprendizagem, a transdução alagmática e a aprendizagem afetiva da gramática dos usos padrões.

Palavras-chave: letramento-cartografia; transdução; alagmática.
\end{abstract}

ABSTRACT: This production reflects on the reductionist practices of teaching grammars and other possible forms of work to be followed, using transduction as a form of reasoning, towards the experience of reading and more serious and fruitful studies that broaden horizons and effect individualizations. Deleuze and Guattari are our main philosophical optics; Neves, Faraco and others served us with their distinct concerns in the area of language teaching; Gabriel Magalhães' texts support our reflections and analyzes, which are concerned with the need to experience cartographic procedures,

\footnotetext{
"Pós-doutor em Letras pela Universidade da Beira Interior de Portugal; pós-doutor em Letras Clássicas pelo Laboratório de Letras Clássicas da Universidade Federal da Paraíba; Doutor em Letras pela Universidade de São Paulo; Professor efetivo da Universidade Federal do Norte do Tocantins - UFNT. E-mail: luizpeel@uft.edu.br.

"* Doutoranda em Letras no Programa de Pós-graduação em Letras da Universidade Federal do Norte do Tocantins - UFNT; Assistente em Administração na Universidade Federal do Norte do Tocantins - UFNT. E-mail: roseliasousasilvao9@uft.edu.br.

**** Doutoranda em Letras no Programa de Pós-graduação em Letras da Universidade Federal do Norte do Tocantins UFNT; Professora efetiva da rede municipal de Araguaína - TO. E-mail: priscilavenncio@gmail.com.
} 
learning flavors, alagmatic transduction and affective learning of the grammar of standard uses.

KEYwoRDs: literacy-cartography; transduction; alagmatic.

\section{INTRODUÇÃO}

Pensar e discutir as gramáticas da língua portuguesa nos cursos de letras é uma tarefa árdua e polêmica: muitos linguistas se afastam dessa empreitada, até mesmo correndo de sua discussão; enquanto que filólogos e gramáticos a discutem sem conseguir que os alunos, e muitos deles vulneráveis em relação à produção escrita concernente ao uso padrão e, também, no que toca à produção oral mais padronizada, aprendam-na com gosto (por seus sabores e saberes), com proficiência e com segurança.

O ensino da gramática tradicionalmente está calcado em raciocínios dedutivos, quando são apresentadas normas e regras genéricas; ou indutivos, quando se parte do texto e caminha-se para a regra. Há, no entanto, uma outra forma de trabalho, que parte das gramáticas familiares e que caminha para a gramática do uso padrão. Esse modo de ensinar usa a transdução como forma de raciocínio.

Essa maneira de pensar as gramáticas se afasta peremptoriamente tanto do modelo pedagógico medieval, usado até os nossos dias, quanto da negação terminológica e conceitual; ora, conceitos são importantes para se pensar a língua, mas conceitos lógicos e bem colocados, que se justifiquem pragmaticamente como parte das atividades de reconhecimento e de exercício das flexibilidades organológicas da língua.

Nesse sentido, a leitura e o estudo belo e sério de textos literários são capitais no universo de quem pretende dominar o conjunto de normas e de variações de uma língua; pois neles, "talvez mais do que em qualquer outro tipo de texto, é visível a diferença das linguagens e dos pontos de vista que ampliam nossos horizontes" (FARACO, 2008, p. 161).

Neste artigo, após algumas linhas sobre o sabor da aprendizagem, caminharemos pela teoria - raciocínio gramatical transdutivo e alagmático enquanto experimentação transdisciplinar madura e profícua; para, depois, por meio de análise de frases de Gabriel Magalhães, premiado escritor português, chegarmos ao uso mais padronizado, ou, em outras palavras mais doces e gentis, a um dos usos elegantes e prazerosos do traçar linguístico/gramatical.

Convém uma exortação: não se preocupem, leitores atentos, com nossa difusão ou prolixidade, se ela de fato ocorrer, pois o que nos interessa são as experimentações alagmáticas - o que ficará claro após a entrada definitiva neste texto (a alagmática pede o múltiplo; tanto em relação aos conteúdos quanto às formas; solicitando, ainda, que os processos de criação sejam trans, isto é, que atravessem áreas de pesquisa, disciplinas, culturas...). 
Dessa forma, então, procuramos nesta escrita, dando continuidade e ampliando outros estudos nossos, refletir aspectos filosóficos para as práticas de ensino; vivenciar os procedimentos cartográficos nos quais o percurso é todo passível de descobertas, de experimentação, de validade; e, ainda, aprender com o caminhar e construir com os múltiplos aprendizados.

\section{SABORES DA APRENDIZAGEM}

Os sabores e os saberes experimentados pelos sentidos são experimentações rizomáticas do letramento-cartografia ${ }^{1}$; o que, infelizmente, tem sido pouco vivenciado, em função da proibição imposta pelo verbo aos sentidos.

Com intuito de refletir essa proibição e o que seria oposto dela, conversemos, a partir de agora, leitor precavido, saboreando pedacinhos apetitosos de palavras, de frases, de períodos, de parágrafos e de secções - assim o esperamos.

No Ocidente, os sentidos foram derrotados pela linguagem verbal, o que foi magistralmente exposto por Michel Serres, nOs cinco sentidos; sendo que o seguinte trecho da obra revela com clareza o que aconteceu com o saborear volitivo-afetivo das coisas pelos sentidos:

O verbo proíbe o sentido, sobretudo aqueles em que ele não tem o que fazer. Triunfante, impõe a proibição, essa organização social da anorexia e do dessabor.

A língua que fala mata na boca a língua que saboreia. Mata-a no coletivo, na que se diz entre nós. Isto, que se diz, reduz-se a um preço. Comerás palavras, mas, com mais frequência, de agora em diante, o código e a cifra. Portanto, ficarás muito, e mais ainda, e sempre mais, enfunado deles. Nada é tão aceito como um código, nada cresce tanto como um número. Engolirás contas. Teu corpo invadirá o espaço, como o próprio verbo levado pelo vento, como a sociedade fundada sobre o verbo.

A teoria que reduz o dado à linguagem é produzida em um coletivo que pratica e vive essa redução, retorna a ele como sua ideologia e o infla; esta expansão hoje impõe a língua desse grupo e sua moeda ao universo inteiro.

Vitória total do doce e do macio (SERRES, 2001, p. 189).

\footnotetext{
${ }^{1} \mathrm{O}$ conceito de letramento-cartografia foi criado por nós, pela repetição e pela diferença que apresenta em relação ao conceito de arte-cartografia, criado por Deleuze. A arte-cartografia se opõe à arte-arqueologia: a primeira repousa sobre coisas relativas ao esquecimento e sobre lugares de passagem; a segunda, sobre o processo pessoal da memória e sobre o ideal coletivo da comemoração (DELEUZE, 2011). Deve compor rizomas com o letramento-cartografia, com a arte-mestiça e com todas as artes menores, já que diz as mesmas coisas que a criança costuma dizer, sendo feito de trajetos e de devires, e suas personagens, conceituais e estéticas, definem-se pelos trajetos que percorrem na realidade ou na virtualidade.
} 
Assim, o verbo proibiu e vem proibindo o sentido: de palavra em palavra, a língua acaba mesmo vindo; o triste é que os sabores se perderam e continuam a se perder, junto com os cheiros, com os gostos, com os sons e com as texturas (ou com os toques). E os cheiros das palavras, junto com os seus gostos, foram se perdendo e deixando a língua insossa.

Já o letramento-cartografia quer não o império dos sentidos, mas a sua conjunção sensível com o verbo; e, por que não, as suas disjunções inclusivas e as suas conjunções exclusivas - daí, verbo e sentido poderão experimentar-se e serem experimentados com sabor e com saber, numa vivência de multiplicidade e de equilíbrio propostos pela cartografia.

O letramento-cartografia quer a conjunção exclusiva do sabor com o saber - quer a disjunção inclusiva do desejo com a alegria. E o desejo, primo da alegria, é com essa e com o apetite uma das essências próprias do humano, o que Spinoza percebeu há tempos (2007, p. 140), deixando proposições belíssimas sobre esse parentesco. O apetite, para o filósofo, é o desejo juntamente com a consciência que dele se tem, dirigidos ambos para a sua conservação (SPINOZA, 2007, p. 140).

Dessa forma, o letramento-cartografia também se dirige para a conservação do humano, para uma defesa de sua vida equilibrada e respeitosa, experimentando o desejo como todo o esforço, como todo o impulso, como todo o apetite, como toda a volição e como toda a afeição (também como todo excesso); e todos variáveis de acordo com seus variáveis estados, que se opõem ou não em sua luta para sobreviver em meios culturais antagônicos e desleais.

O letramento-cartografia mantém os sabores, acrescentando saberes: o que quer também a abordagem alagmática da transdutividade gramatical, experimentada pela junção de dobras pragmáticas, epistemológicas e teóricas.

\section{ATRANSDUÇÃOALAGMÁTICA:PROCEDIMENTONOLETRAMENTO- CARTOGRAFIA}

O início desta explanação acerca dos conceitos de transdução e alagmática pode ser trilhado com um trecho do Abecê Filosófico da Arte-cartografia que nos diz:

a etimologia do vocábulo 'transdução' ajuda a entrar em seus significados: trans ('através') + dução ('conduzir'); assim, os processos transdutivos dizem respeito à condução através de níveis ou de categorias ou de mudanças, ou ainda de metamorfoses (ou transmorfoses) artístico-cartográficas (OLIVEIRA et al., 2020, p. 121).

A vivência dos processos transdutivos se constitui como descoberta transfiguratória, em que as atividades partem do ser e se estendem em diversas e múltiplas direções e dimensões; 
almejando ao devir e às individuações. E os seus principais vetores são a potência, o afeto e a apresentação, posto que deixa de lado as possibilidades, as afeições e as representações.

Por transdução entendemos "uma operação física, biológica, mental, social, pela qual uma atividade se propaga gradativamente no interior de um domínio, fundando esta propagação sobre a estruturação do domínio operado de região em região" (SIMONDON, 1964, p.18, apud DAMASCENO, 2007, p. 178); transdução é, então, um processo relacionado a ações e a regiões. De fato, "cada região de estrutura constituída serve de princípio de constituição à região seguinte, de modo que uma modificação se estende progressivamente ao mesmo tempo que esta operação estruturante" (SIMONDON, 1964, p.18, apud DAMASCENO, 2007, p. 178).

$\mathrm{Na}$ aprendizagem linguística e/ou gramatical, há transdução quando os agenciamentos e as experimentações partem do ser, tanto de seu centro quanto de um fora, e, por meio de processos alagmáticos - processos trans, que misturam e mesclam saberes e sabores -, estendem-se em diversas direções, como se múltiplas dimensões do ser surgissem ao redor de experimentações.

A experimentação da transdução é sempre alagmática; nunca, de fato, está associada a disciplinas rígidas e estanques - o processo familiar de aprendizagem das línguas e das gramáticas exemplifica bem a vivência transdutiva e alagmática dos bebês com a gramática - sempre holística e íntegra.

Já que citamos o termo alagmática, convém explicitá-lo um pouco mais: alagmática é o nome dado por Gilbert Simondon ao processo que opera a individuação - é, de fato, o acontecimento que dá forma a uma nova fase do ser. O termo vem do grego alagmé - "troca", "mistura", acrescentando nuanças relativas a trocas e a misturas; daí, pode-se conceituar alagmática como a teoria geral das trocas e das mudanças de estado ou de afeto. No tocante ao letramento-cartografia, a alagmática se constitui como um processo associado à transdução que mistura a arte com a ciência e com a filosofia, além da troca com outras formas de pensar e de sentir constitutivas de agenciamentos e experimentações menores.

As experimentações alagmáticas renovam constantemente o ser, ocorrendo esse processo por meio das resoluções de problemas pragmáticos, com a amplificação e com a individuação, ou seja, com a tomada de forma e com a passagem de um estado a outro; desse modo, as experimentações alagmáticas do letramento-cartografia atualizam também o ser, ou por meio da tomada de forma e de passagem do silêncio à emissão de frases monorremáticas, ou da folha vazia aos primeiros gramas - aos primeiros traços, às primeiras garatujas e às primeiras letras, ou do cenário vazio à conjunção da gestualidade da dança com a sonoridade da música, ou por qualquer outro processo criativo que leve a criança a criar².

\footnotetext{
${ }^{2}$ Conforme as matrizes de criação da linguagem de Peirce, com o que concorda Deleuze, há três planos para a criação e para a recepção semiótica: a primeiridade - matriz musical; a secundidade - matriz visual; e a terceiridade - matriz verbal - que se constituem como categorias que devem ser trabalhadas alagmaticamente no processo do letramento-cartografia.
} 
A transdução acrescenta, ainda, outros remas para a experiência criativa alagmática, acarretando a descoberta de dimensões éticas, estéticas e lógicas, a partir das quais se define uma problemática que, posteriormente, transformar-se-á em devir. Ribeiro nos ajuda a compreender a extensão alagmática do conceito (2010, p. 23): "a transdução é o próprio ser se fazendo e que o ser é esse se fazer, a relação é, portanto, constitutiva da existência".

Em suma, a transdução pode ser resumida como um fluxo de passagem de um estado pré-individuação (realidade não individuada) ${ }^{3}$ para um estado de transindividuação. Adaptando a noção de individuação transdutiva para o campo da linguagem, ponderemos que a partir do momento em que o indivíduo recebe estímulos linguísticos e gramaticais do meio social, um sistema interno (de ressonância coletiva, visto que a língua pode ser considerada um indivíduo técnico que atravessa a construção social humana) é ativado, desencadeando um conjunto de respostas que possibilita a materialização linguística e gramatical num objeto técnico ${ }^{4}$ concreto à maneira de Simondon - um gênero textual, por exemplo.

Para essa abordagem transdutiva, as gramáticas são técnicas constituídas a partir de conjuntos de traços adquiridos, inicialmente, no seio da família; e cujo processo de apropriação é, como vimos salientando, transdutivo e alagmático, já que se constitui como técnica de traçar frases harmônicas cuja experimentação, na família, é transdutiva e alagmática, o que não acontece na experiência escolar, na qual a aprendizagem das gramáticas deixa de ser vivenciada dessa forma.

O traçar letras, morfemas, palavras, orações, frases, períodos, parágrafos e textos é uma forma sempre organológica de compor; é, alagmaticamente, uma conjunção exclusiva nos planos sintagmáticos e uma disjunção inclusiva nos planos paradigmáticos. Ora, conforme escreveu Edward Sapir, já em 1924, toda manifestação da linguagem verbal, ou seja, toda norma ou variedade linguístico-gramatical tem organização e gramática - tem "plenitude formal" (SAPIR, 1924, apud FARACO, 2008, p. 35); para nós, tem traçados organizados, enquanto objetos técnicos, como conjunção e disjunção de traços menores, os quais, por sua vez, são também traçados organicamente por conjunção e disjunção de traços menores ainda, componentes dos maiores - um dos paradoxos linguístico-gramaticais que dão sentido às expressões da língua, já que a conjunção ocorre concomitantemente à disjunção.

De fato, no plano sintagmático ocorrem conjunções sempre que emitimos uma frase, desde as frases monorremáticas do bebê até as frases mais complexas com subordinações e coordenações concomitantes de pensamentos. Nesse plano, a intenção ou a escolha do utente linguístico se dá por associação, conjuntiva e exclusiva (já que, procurando associar para formar sua mensagem, o utente conjuga formas escolhidas, excluindo uma grande variedade

\footnotetext{
${ }^{3}$ Oliveira (2015).

${ }^{4}$ Para Gilbert Simondon, também para Stiegler, não há uma ruptura essencial entre o humano e o não-humano - entre sujeito e objeto técnico; sendo a técnica, para essa postura pragmática, um verdadeiro modo de existência. Para Neves (2006), os objetos técnicos estão articulados de modo íntimo com o humano por meio de processos transdutivos.
} 
de outras) -, associação de fonemas, associação de morfemas, associação de palavras, associação de orações, associação de frases e associação denotativa, referencial ou conotativa. E, de associação em associação, são formadas as frases. Até a frase mais simples do bebê tem associações de fonemas, de morfemas e de ostensão (já que as frases monorremáticas iniciais têm uma função ostensiva ou indicadora do ser - da mãe, por exemplo).

Paradoxalmente, na mesma enunciação, só que em outro plano, desta vez no paradigmático, ocorrem exclusões; nesse plano, a intenção ou a escolha do utente linguístico se dá por substituição, disjuntiva e inclusiva (já que, a partir de um conjunto muito grande de formas, o utente escolhe uma, retirando-a de seu conjunto, e a inclui em sua enunciação) -, substituição de fonemas, substituição de morfemas, substituição de palavras, substituição de orações, substituição de frases e substituição denotativa, referencial ou conotativa. E, como dito no parágrafo anterior, só que desta vez em relação aos paradigmas, até a frase mais simples do bebê tem, na sua origem semântico-pragmática, substituições de fonemas, de morfemas e de ostensão.

Como são duas operações pragmaticamente concomitantes, a conjunção exclusiva e a disjunção inclusiva estabelecem paradoxalmente a "plenitude formal" do traçar linguístico, permitindo que as gentes se comuniquem e se interajam proficuamente; seja através da arte, da filosofia, da ciência ou de outra forma qualquer de comunicação e/ou interação, randômica ou intencional.

O traçar linguístico é processualmente uma ação transdutiva, constituindo-se linguisticamente e gramaticalmente como uma abertura dos contextos aos acontecimentos (MACKENSIE, 2003). Enfim, para retomar e finalizar este tópico, o bebês produz as suas frases por transdução, uma vez que todas as suas enunciações são aberturas ou deiscências de seus contextos de vida familiar para os acontecimentos de sua vida individual.

\section{A TRANSDUÇÃO E A APRENDIZAGEM DA GRAMÁTICA DOS USOS PADRÕES}

Iniciemos este excerto do artigo com o primeiro exemplo tirado do livro Madrugada na Tua Alma, de Gabriel Magalhães (2011, p. 154): "A dama e o cão gastavam assim a tarde, conversando pedacinhos de comida" ${ }^{\prime \prime}$. Dessa frase destaquemos a morfossintaxe das classes

\footnotetext{
${ }^{5}$ O bebê é um ser unívoco, dizendo-se de todas as maneiras num mesmo sentido; e é esse excesso em relação ao dizer-se que vai constituir o que chamamos de desejo. Desejo é, para a esquizoanálise de Deleuze e de Guattari, o excesso de afetos e de sensações do dizer.

${ }^{6} \mathrm{O}$ trecho foi escolhido não só por sua simplicidade em relação ao saber gramatical necessário para sua compreensão, mas também por seu sabor semântico.
} 
de palavras ${ }^{7}$ que a compõem: temos dois nomes substantivos precedidos por artigos e unidos pela conjunção 'e', que formam o sujeito composto ('a dama e o cão'); um verbo com transitividade ('gastavam'); um nome que serve de complemento ao verbo e que está precedido pela partícula adverbial 'assim'; e uma expressão adverbial oracional com verbo na forma nominal, cujo núcleo nominal associado ao gerúndio do verbo 'conversar' compõe uma explicação apositiva ao advérbio 'assim'.

O professor Henrique Graciano Murachco sempre afirmava em suas aulas de grego e de latim que a melhor forma de se ensinar uma língua era pela morfologia (o professor Henrique alargava o conceito tradicional de morfologia, ampliando-o para algo que alguns hodiernamente chamam de morfossintaxe). Neste artigo, seguimos inicialmente as orientações do mestre.

Para ele, assim como para Deleuze e Guattari, o que mais importa na experimentação linguística e gramatical é a vivência do texto em seus vários usos, sendo que o uso linguístico e/ ou gramatical padrão é uma das metas da escola - o uso maior; enquanto que os usos menores devem ser respeitados e experimentados com o mesmo zelo e cuidado.

A criança, na convivência linguística familiar, usa com abundância e com precisão comunicativa a gramática utilizada pelos pais, irmãos, avós, tios e por outros utentes linguísticos com os quais convive. Assim, após um período de garatujas fonéticas, constrói inicialmente frases remáticas orais, mais precisamente frases monorremáticas ${ }^{8}$, a partir de nomes substantivos até chegar aos verbos e às frases declarativas. Dessa forma, comendo com encantamento pedacinhos de palavras, ou conversando pedacinhos de comida, a criança deixa de ser infante (o ser que não fala) e passa a falar pelos cotovelos, pelo nariz, pelos olhos e pelos ouvidos, numa conjunção inclusiva de saberes e de sabores.

A transdução é uma experimentação "espontânea", que pede os sabores providenciados pelos sentidos. Esses sabores, inicialmente, são real e virtualmente vivenciados nas frases monorremáticas, cuja experimentação é sempre afetuosa, com a mãe, com o pai ou com outro indivíduo que estiver presente nos momentos criativos do bebê.

A aprendizagem gramatical do uso padrão, sendo transdutiva, constituir-se-á numa aprendizagem menor por respeitar, como vimos dizendo, a cultura das minorias - o que a torna evidentemente alagmática, por atravessar várias disciplinas, tanto maiores e menores, e igualmente várias culturas, tanto maiores quanto menores.

Voltando ao nosso trecho, o excerto citado de Magalhães, o período se inicia pela conjunção de artigo mais nome substantivo com um outro sintagma formado por artigo e nome substantivo, aos quais se unem um verbo - um rema propriamente dito - e uma expressão

\footnotetext{
${ }^{7}$ Por morfossintaxe das classes de palavras entendemos os conceitos, as classificações e os usos padrões das categorias gramaticais no nível da palavra.

${ }^{8}$ Frases monorremáticas são frases com um só rema - com uma só palavra; rema vem do grego e significa "o que é dito" (o resultado do dizer ou a coisa mesmo dita) Em rema, o sufixo 'ma' significa objeto ou resultado; a raiz 're', dizer - o lékton.
} 
nominal que completa o rema (novamente artigo mais substantivo; só que, desta vez, há a injunção também de um advérbio, que já solicita o complemento da mensagem).

Essas noções - substantivos, artigos, verbos, advérbios e remas -, infelizmente, não são dominadas com lucidez, nem de saber nem de sabor, pelos alunos de nossos cursos tocantinos da área das letras e das pedagogias; principalmente o rema (ou verbo) - o vocábulo que marca o acontecimento linguístico e gramatical.

Para a filosofia do acontecimento, cuja origem remota chega até os estóicos e cujo desenvolvimento hodierno chega até Deleuze e Guattari, o rema é o que importa (o lékton), constituindo-se como o acontecimento do dizer - o que a criança experimenta com intensidade, diferentemente dos adultos, que muitas vezes só falam e não dizem nada, o que faz com que seres e coisas não aconteçam.

Façamos uma pequena digressão, cotejando a noção de lékton com a de lógos: lógos é a razão substancializada em sentido, a racionalidade: o termo lógos na cultura grega significa indivisivelmente tanto a fala humana quanto a rede sensata e inteligível do mundo. Essa compreensão do termo vem da origem da filosofia ocidental - dos pré-socráticos, de Platão e de Aristóteles.

Mas há o paradoxo estóico de lógos, o lékton - o acontecimento do dizer, que, ao contrário do lógos, constitui-se na compreensão filosófica como um incorporal. Os estóicos também usavam o termo lógos, mas com dupla acepção - lógos endiathétos ("interior ao mundo" - um sentido anterior à lógica) e lógos prophorikós ("lógos proferido" - a retomada e a sublimação). Porém, o que mais importava aos estóicos era mesmo o lékton, para o qual reconheciam nove tipos, sendo o mais importante o axioma ou proposição. Assim, lógos e lékton alternaram-se na escolha dos filósofos como fundamentos de suas lógicas - o lógos remete ao transcendental no nascimento da filosofia clássica; já o lékton, ao imanente, não só para os estoicos, mas para Merleau-Ponty e para Deleuze.

Para o letramento-cartografia, o que importa é o sentido enquanto acontecimento, o efeito incorporal da e na linguagem - o lékton e não o lógos. Deleuze os chama de fantasmas, posto não existirem propriamente, não estando presentes nas coisas, somente na linguagem. E, nela e por ela, subsistem ou insistem enquanto diferença, como caosmos - uma disjunção inclusiva entre caos e cosmos, que passa ainda pela osmose - um devir, uma simbiose, uma simpatia entre caos e cosmos.

E é com esses fantasmas que a imaginação da criança brinca, criando garatujas fonéticas e, posteriormente as frases monorremáticas; sempre transduzindo, sempre misturando e sempre trabalhando, ao menos em sua produção inicial, como corpos-sem-órgãos.

Para a dama e o cão gastarem a sua tarde, os pedacinhos de comida conversados foram necessários; e ainda o são. Se, de um lado, temos o rema, composto pelo verbo, por seu complemento e por seu aposto circunstancial; de outro, temos os substantivos, tanto em seu 
uso referencial quanto denotativo e ainda metafórico; já que no romance se referem mimeticamente a seres concretos, denotando intencionalmente um conjunto de propriedades, indicando extensionalmente uma classe e metaforizando, por outro lado, afetos.

O rema é, de fato e de fenômeno, o que faz a frase acontecer, é que lhe dá sentido; afinal, a dama e o cão gastaram a sua tarde, e gastaram-na conversando pedacinhos de comida - tudo o que foi dito da dama e do cão constituem o rema.

\section{OS REMAS, OS ENGRAMAS E O LETRAMENTO MENOR}

Citemos uma outra frase da mesma obra de Gabriel Magalhães (2001, p. 156): “Em Santa Margarida, criavam-se a pontapé limpo uns cães da raça pit bull, uns animais completamente psicopatas - que uivavam de noite e eram atirados aos mancebos, num derradeiro teste à sua bravura militar". O lékton principal desse enunciado é 'criavam' mais a partícula 'se'; assim, a conjunção "criavam-se [...] uns cães da raça pit bull" contém acontecimento e substâncias - o que basta para a frase ser percebida como gramaticalmente padrão. Entretanto, há ainda atributos, tanto verbais quanto nominais (noções adverbiais e adjetivais), que dão o fecho aos engramas relacionados ao que é dito.

Engramas são, o que é muito importante no universo marcante dos bebês e das crianças, as marcas cerebrais deixadas por cada uma de nossas experimentações, inclusive, e principalmente, as linguístico-gramaticais; nos estudos da neuropsicologia, engramas se referem às formas como as memórias são hipoteticamente guardadas em função das mudanças biofísicas ou bioquímicas nos tecidos neurais, sempre em respostas a estímulos (OLIVEIRA et a., 2019).

Engramas são desenvolvidos por meio de transduções alagmáticas; sendo que uma das funções do letramento-cartografia é possibilitar o desenvolvimento de engramas rizomáticos, ou seja, o desabrochar de marcas lineares e não pontuais que sejam realmente e virtualmente mestiças e menores em relação a todos os sistemas de poder envolvidos e que envolvem a produção da linguagem verbal (essas marcas constituem os repertórios de cada indivíduo). Os engramas constituem, ainda, as marcas que definem para o ser toda a sua cultura, todo do seu processo de individuação transdutivo.

Voltando ao letramento-cartografia, já que o seu processo é transdutivo e, portanto, criador de engramas, ele é responsável pela manutenção, ao lado do que é aprendido da cultura maior, das culturas menores de cada indivíduo.

E menores por tomarem parte do que é menor e diferente em relação ao poder; por quererem afetos mestiços, com a inclusão do terceiro. Nos processos de recepção e de criação em letramento-cartografia, o que importa é, inicialmente, o letramento menor, ou seja, o letramento enquanto saúde; e isso só ocorre quando os agenciamentos e as experimentações linguístico-gramaticais são vivenciados enquanto passagens ou devires. 
Parafraseando e parodiando Deleuze (2016), um letramento menor não é o de uma forma ou de uma expressão menor, mas antes o que uma minoria faz por meio de desvios e/ou errâncias e/ou flanares de formas ou de expressões maiores. O letramento menor apresenta, então, as seguintes características: forte coeficiente de desterritorialização, intenso caráter político e extremo valor coletivo.

O letramento menor é necessário para que sejam estabelecidas passagens como territórios políticos e como conjuntos de rizomas coletivos; ou seja, nos procedimentos do letramento-cartografia, principalmente na educação infantil, o indivíduo deve ser estimulado a vivenciar concomitantemente tanto os processos de criação quanto de recepção; deve ser um escrileitor, ou mais propriamente, já que se trata da experimentação alagmática de múltiplas e mistas formas de expressões artísticas, deve experimentar-se como autor e contemplador ao e no mesmo devir.

E a volição desejada como excesso nesses procedimentos linguístico-gramaticais é a vontade de dar, que, segundo Nietzsche, é o nome verdadeiro da virtude que convém à educação, à arte e à filosofia, e também ao letramento-cartografia, constituindo-se como um sentimento indizível e inexprimível, somente vivenciado enquanto intuição ou percepto artístico-cartográfico.

Nos agenciamentos e nas experimentações do dar, o sim e a ação triunfam em relação ao não e à reação; e a percepção do valor dos sentidos e da totalização plural triunfam igualmente sobre a interpretação e sobre a representação. O importante é a multiplicidade de agenciamentos e de experimentações imanentes como dispositivos para a fruição de linhas e rizomas que sejam real e virtualmente fluxos e cortes de fluxos que almejam o devir linguístico-gramatical.

No letramento menor, por sua natureza alagmática, todas as formas de expressão ganham passagem - de fato, as artes musicais, as artes dramáticas e as artes visuais, puras ou mistas, ganham valores dionisíacos, o que era atribuído por Nietzsche somente à música; $\mathrm{e}$ por quê? Porque deixam de ser meros reflexos de aparências, alçando valores anteriormente atribuídos e vivenciados pela música com grandiosidade ímpar, já que são experimentadas criativamente como reflexos da vontade (o lirismo gráfico de Miró, ou o de Klee, constitui-se esplendorosamente como reflexo das vontades do artista, da sua vontade de dar; e, ainda, da vontade de receber, e de dar para si mesmo, de quem aceitar criativamente os seus perceptos).

Assim, a vivência artístico-cartográfica do letramento infantil, enquanto processo de uma educação menor, permite o desmedido, o deserto, o múltiplo, o diferente, o incerto, o assustador, o descomunal e o háptico - o dionisíaco.

O letramento menor, ou cartográfico, cria corpos sem órgãos, sem braços e sem mãos, nos quais a forma e a matéria reinventam a própria vida, produzindo singularidades pela interação com outros corpos sem ou com órgãos; daí a necessidade da interatividade randômica 
nos letramentos-cartografias da contemporaneidade (o randômico é sem órgãos por excelência fenomenológica).

\section{O EXCESSO DO AFETO MENOR NO LETRAMENTO-CARTOGRAFIA}

Como começamos cada parte de nosso texto com trechos de Magalhães, um outro excerto nos ajudará a discorrer sobre a importância do afeto no letramento-cartografia: "Ao entrar no prédio da maior biblioteca pública portuguesa, Roque tremia, com um receio enorme de que o obrigassem logo a ler qualquer coisa” (MAGALHÃES, 2011, p. 159).

Há crianças que odeiam leituras, gramáticas e matemáticas; tendo mesmo receios enormes de se aproximarem dos saberes e dos sabores, por faltar-lhes o afeto associado à alegria em relação às ações de desvendar e de criar traços e números, e sobrar-lhes, ainda e pelo contrário, o conjunto de afetos associados ao medo e ao fracasso.

Ora, afeto associado à alegria diz respeito à mudança de intensidade, à variação da potência de agir e da existência, sendo importantíssimo fator para a aprendizagem e, consequentemente, para o letramento-cartografia. Durante muito tempo, a tradição filosófica deu primazia à razão em detrimento dos afetos, considerando-os como vícios que levariam o homem a precipitar-se ao erro. Desse modo, as paixões deveriam ser reprimidas para que a razão tivesse livre fluxo.

Espinosa, entretanto, defende que não é possível que seja estabelecida uma distância entre seres e afetos, uma vez que os seres, naturalmente e necessariamente, afetam-se na interação contínua dos encontros de corpos e de ideias. E é a partir dos encontros, do fluxo, que as afecções são produzidas. Essa produção, segundo Espinosa, tem a alegria, o desejo e a tristeza como afetos primários geradores de todos os diferentes afetos, mas ela pode ser entendida em diferentes graus de complexidade. Os afetos podem ser passivos ou ativos e é por meio deles que o homem atualiza seus estados e potências.

Os afetos passivos são da ordem das paixões, sendo, portanto, mediados pelo gostar e pelo prazer. Tais afetos podem tanto aumentar quanto diminuir a potência de agir. Quando uma afecção aumenta, a potência de agir, isto é, quando há o encontro de algo que se compõe com o ser, com algo que compõe com o indivíduo, é experimentada uma afecção denominada alegria-paixão, e passa-se de uma perfeição menor para uma maior, uma vez que o conatus ${ }^{9}$ aumenta.

\footnotetext{
9 Segundo Espinosa, cada ser humano possui uma essência singular denominada conatus que constitui sua potência atual, a perseverança em permanecer em seu ser enquanto puder. Mas o conatus também é abertura para ser afetado, sendo, portanto, relativo ao desejo, isto é, "todos os esforços, todos os impulsos, apetites e volições do homem, que variam de acordo com o seu variável estado" (SPINOZA, 1997, p. 239). Conatus também é esforço; em grego é hormé - "impulsão natural pela qual o ser se conserva"; designando, ainda, a tendência para se movimentar, pôr-se em marcha.
} 
O inverso acontece com uma afeção tristeza-paixão ${ }^{10}$, o encontro com um corpo que não se compõem com o do indivíduo que experimenta o agenciamento, gera uma diminuição da potência de agir, o que obriga a passar de uma perfeição maior para uma outra menor, uma vez que o conatus, em sua auto perseverança no ser, repele tudo aquilo que possa detê-lo. Isso ocorre porque em um encontro os corpos podem ter tanto uma relação de composição quanto de decomposição.

Segundo Deleuze (1968, apud IAFELICE, 2015), o que define a qualidade desse encontro é o critério do útil, isto é, pode-se dizer que o encontro é bom quando ambos os corpos se compõem e progridem juntos, o contrário disso resulta em um mau encontro.

É importante salientar, contudo, que, conforme explica Espinosa, um afeto passivo sempre pressupõe impotência na medida em que está direcionado sempre à sua própria manutenção, ou seja, quando em uma afecção tristeza-paixão é estabelecida uma relação com um objeto que não se compõe com o ser, a potência diminui, não porque haja menos potência, mas porque ela está limitada a manter o afastamento desse objeto. O mesmo acontece em uma afecção alegria-paixão, embora a potência de agir aumente diante de um bom encontro, todo esforço está direcionado a conservar a alegria e a relação com o objeto que a promoveu.

Desse modo, em ambos os casos, existe uma relação de instabilidade e de dependência, isso porque, retornando a Deleuze (1968, p. 211), "[a] potência de agir está imobilizada, fixada, determinada a investir à afecção passiva”; aqui, a ação é, portanto, determinada por causas exteriores, por ideias inadequadas, não pelo próprio conatus.

Por outro lado, os afetos ativos configuram ações determinadas pelo alcance da própria potência do pensar do ser, por um conhecimento objetivo, por uma ideia adequada, cujas razões internas de sua produção são apreendidas pelo intelecto, de forma que pela razão o indivíduo se torna a sua causa. Aí se revela a importância e a função dos afetos passivos, principalmente na afecção alegria-paixão.

Conforme explica Espinosa, pode-se, por meio da razão, formar noções comuns em torno das paixões-alegres, transformando-as em ideias adequadas e, por conseguinte, em ação. Formar noções comuns significa perceber, por meio da razão, elementos que estão tanto em si quanto em outro corpo.

Em letramento-cartografia, os afetos ativos criam signos igualmente ativos em sua capacidade de potencializar perceptos e de criar relações de composição; já na contemplação artístico-cartográfica mais ampla, como, por exemplo, nos casos da literatura ergódica digital, os afetos passivos são da ordem da alegria-paixão ampliada sinestesicamente, aumentando a potência de agir, ou vontade de potência, pela criação de conjuntos de sensações - os perceptos.

\footnotetext{
${ }^{10}$ É preciso ressaltar que, embora Espinosa estabeleça essa distinção entre as afecções, elas ainda se revelam abstratas, uma vez que podemos, de uma forma mais complexa, amar ou odiar um mesmo objeto e com ele interagir de modos imprecisos.
} 
Os perceptos não são percepções, nem dependem do estado ou da situação daqueles que os experimentam (DELEUZE, 2016); constituem-se, para o filósofo, como conjunto de sensações, que valem por si mesmas, excedendo qualquer ser ou coisa vivido: "a obra de arte é um ser de sensação, e nada mais: ela existe em si” (DELEUZE, 2016, p. 194); e o contíguo de efeitos e de impressões produzidas pelas obras de arte é o que constitui o percepto - daí a importância enorme da literatura infantil, e das outras artes, em todas as fases do letramento-cartografia.

Pela arte, os perceptos são arrancados das percepções dos objetos e dos estados de um sujeito percipiente (DELEUZE, 2016, p. 197); e, relacionados com os afetos, são criados pelos artistas como metamorfoses de mundo. Questões e resposta de Deleuze nos ajudam a compreender o seu conceito de percepto:

Que estranhos devires desencadeiam a música através de suas 'paisagens melódicas' e seus 'personagens rítmicos', como diz Messiaen, compondo, num mesmo ser de sensação, o molecular e o cósmico, as estrelas, os átomos e os pássaros? Que terror invade a cabeça de Van Gogh, tomada num devir girassol? Sempre é preciso o estilo - a sintaxe de um escritor, os modos e ritmos de um músico, os traços e as cores de um pintor - para se elevar das percepções vividas ao percepto, das afecções vividas ao afecto (DELEUZE, 2010, p. 200-201).

Os afetos da alegria, para Deleuze (aula de 24 de janeiro de 1978), funcionam como um trampolim, combatendo a tristeza e fazendo passar por dificuldades ou por problemas; com isso, para o filósofo, a alegria traz inteligência- à qual podemos acrescentar, como efeitos da própria alegria, a imaginação, a intuição, a memória e outros afetos que ajudem a auferir perceptos. Nas experimentações artísticas, os afetos (signos artísticos) criam genuinamente perceptos de alegria criativa, o que é fundamental no processo educativo do letramento-cartografia.

Retornemos ao texto de Magalhães (2011): "Ao entrar no prédio da maior biblioteca pública portuguesa, Roque tremia, com um receio enorme de que o obrigassem logo a ler qualquer coisa”. No excerto, 'tremia' é o acontecimento principal da frase - o seu rema básico; enquanto que 'Roque', a sua referência substantiva; envoltos os dois, substantivo e rema, por sintagmas adverbiais de tempo/lugar e de modo, além de outro sintagma substantivo que complementa o substantivo presente no núcleo do segundo sintagma adverbial (é marca estilística do autor esse uso).

O acontecimento experienciado pelo 'tremia' se repete demasiadamente nas escolas tocantinas: os alunos, e alguns professores, tremem quando precisam ler, quando precisam escrever, quando precisam interpretar; enfim, estremecem quando precisam assumir ações 
culturais conscientes. Falta-lhes então afetos de alegria em relação à experimentação da cultura 'livresca' - falta-lhes a vontade de saborear.

\section{GRAMAS E GRAMÁTICAS}

Os gramas, de onde surgiram as gramáticas, são traços em grego clássico; são os riscos traçados nas tabuinhas de barro, tanto na escola quanto nos outros ambientes gregos nos quais a escrita era necessária. As gramáticas são, portanto, técnicas de traçar ou de compreender os traços $^{11}$, constituindo-se posteriormente como conjunto de normas ou regras do bem dizer, mas esse não era o seu uso inicial.

Risquemos, agora, um excerto mais longo da obra de Magalhães (MAGALHÃES, 2011, p. 188-189), para uma tentativa de apropriação das técnicas dos gramas:

Por vezes, também acontecia serem eles que iam brincar para a casa de Rita. As boas famílias de Amarante intercambiavam entre si presentes de fruta, cestinhos de pêssegos acondicionados numa renda de folhas fofas, ou pequenos açafates de morangos vermelhejantes, emprestando-se também mutualmente, de vez em quando, as respectivas crianças. A Quinta dos Ataídes, como era chamada a propriedade do Prof. Nunes da Silveira, dava muito medo. Quando se entrava, o portão de ferro rangia de um modo que arrepiava a espinha. Era uma facada sonora, pelas costas abaixo. Depois vinha um silêncio de túmulo, onde as altas árvores da propriedade, carvalhos de galhos enlouquecidos, conversavam perigosamente conosco. Olhava-se para aqueles ramos e sentia-se uma teia de aranha a formar-se-nos na alma. Em dias muito tristes, particularmente chovidos, pendiam das ramagens fantasmas alvacentos. Dentro do casarão, as coisas pioravam. Os móveis tinham um debrum de sombra, uma escuridão impregnada que cheirava a frio e a mofo. As bolachas do lanche vinham amolecidas e sabiam a papelão. Quem tomava conta deles era uma empregada com um acentuado estrabismo, a Gregória, uma rapariga até bem-disposta, que tentava amenizar um pouco as sombras do ambiente. Cantava na cozinha umas baladas nostálgicas, que ouvia no seu pequeno rádio de pilhas: a sua voz retorcia-se toda em guinchos melódicos muito rebuscados.

Este texto narra lembranças do herói do romance, Miguel Ângelo Stockler, memórias de quando visitava a casa de Rita - a parente que tinha notícias da obra que procurava (o romance trata da busca de um livro perdido, obra que contém os segredos de Portugal).

\footnotetext{
${ }^{11}$ A gramática de Dionísio Trácio foi criada para ensinar a ler, o que era complicado naqueles dias em que as palavras eram escritas sem separação, sem pontuação, sem minúsculas e sem outros elementos gráficos que ajudassem na leitura verbal.
} 
Destaquemos o primeiro período do segundo parágrafo do trecho citado: "A Quinta dos Ataídes, como era chamada a propriedade do Prof. Nunes da Silveira, dava muito medo". O acontecimento marcado pela frase está indicado pelo verbo 'dar', em seu uso pretérito e imperfeito, e com base lógica referencial mimética - sujeito formado por substantivos próprios usados referencialmente; sendo indicado ainda um outro acontecimento por meio de traços verbais, articulares, conjuncional, preposicionais e nominais usados de modo explicativo ou expositivo - "como era chamada a propriedade do Prof. Nunes da Silveira”.

A função referencial, ou ostensiva, dos nomes próprios é utilizada pelo bebê, quando, por meio de suas individualizações linguístico-gramaticais e por meio de suas frases monorremáticas, chama, enaltece ou se refere a sua mãe. 'Mamã', para ele, é utilizado como nome próprio, como referência realmente própria ao ser que o gerou.

Daí, transduzindo alagmaticamente, o bebê alcança, com o tempo e com o uso, a repetição do termo e do conceito de mãe a outras mulheres; e, da mesma forma, transduz nomes comuns, antes de uso ostensivo, a seres comuns e a usos denotativos comuns.

E o 'muito medo' aparece na frase seguinte: “Quando se entrava, o portão de ferro rangia de um modo que arrepiava a espinha". Dessa vez, o acontecimento é marcado pelo rangido do portão de ferro que chegava a arrepiar a espinha; temos vários traços que riscam o medo: verbais, que marcam o eventos, tanto o principal quanto o secundário; nominais, que o embasam logicamente e referencialmente de modo mimético; conjuncionais, que ligam e que indicam o tipo de circunstância; preposicionais, que relacionam, unem e transformam categorias lexicais; articulares, que evidentemente articulam informações de modo também referencialmente mimético; e pronominal, que indica de forma indefinida e genérica seres que entraram ou que entrarão pelo portão; e ainda virgulares.

A frase seguinte continua a traçar gráfica e semanticamente o 'muito medo': "Era uma facada sonora, pelas costas abaixo". Agora o traço frasal contém um único rema - um único lékton -: o verbo 'ser', indicador do acontecimento em sua potencialidade, em sua ocorrência pontual e não ligada ao tempo somente em sua realização passada, mas a todas as vezes, passadas, presentes ou futuras, em que o fato aconteceu, acontecesse ou viesse a acontecer (o que ocorre também com o 'quando' que inicia a frase analisada no parágrafo anterior). A vírgula que separa 'sonora' da expressão adverbial 'pelas costas abaixo' foi traçada para separar dois atributos, o nominal 'sonora' do adverbial 'pelas costas abaixo', que caracterizam o tipo de 'facada' (elementos de mesmo valor semântico-pragmático costumam ser separados por vírgula).

O quarto período opõe som e silêncio: "Depois vinha um silêncio de túmulo, onde as altas árvores da propriedade, carvalhos de galhos enlouquecidos, conversavam perigosamente conosco"; acrescentando, pelo traçado adverbial de lugar expresso por onde, nuanças locativas ao silêncio. Há a continuação do 'muito medo' - tema deste parágrafo, caracterizado pelo acontecimento da vinda do silêncio tumular e por meio da conversa perigosa dos carvalhos 
enlouquecidos. Os traços presentes na frase são verbais, nominais, articulares, adverbiais, pronominais e de pontuação.

A quinta frase continua a traçar o 'muito medo': "Olhava-se para aqueles ramos e sentia-se uma teia de aranha a formar-se-nos na alma”. Contém três acontecimentos: a ação de olhar, a de sentir e a de formar; tudo isso por meio de verbos, pronomes, preposições, substantivos, conjunção e artigos, numa profusão sensível e pragmática do traçar literário.

No período seguinte, há ainda traços do 'muito medo': "Em dias muito tristes, particularmente chovidos, pendiam das ramagens fantasmas alvacentos". Desta vez são 'fantasmas alvacentos' que 'pendiam das ramagens' nos 'dias muito tristes'; nesse trecho, traços verbais e nominais são caracterizados por meio de atributos dirigidos à intensidade do medo.

Dessa forma, gramas e engramas se relacionam no texto literário, formando afetos e sensações, estimuladores, por sua vez, de perceptos persistentes e enriquecedores dos próprios afetos e sensações. Os gramas traçados por engramas do artista provocam engramas no leitor, sendo eles os fixadores dos perceptos.

\section{MAIS ENGRAMAS E GRAMAS}

Mais alguns engramas e gramas do artista podem ajudar a experimentar o traçar estilístico das gramáticas:

Aquele mutismo suspenso, de gaivota a pairar, fazia pensar nos ecos da sala de estar de uma pessoa reformada.

Em volta, mais algumas pessoas se curvavam sobre livros, com gestos lentos, de gota que cai de uma torneira mal vedada.

Mesmo ao pé de uma janela, avistava-se um fulano esguio, todo ladrilhado de luz, que escrevia de um modo pensativo, flutuante (MAGALHÃES, 2011, p. 160).

A gramática de Gabriel Magalhães é próxima dos usos padrões do português europeu; e nesses três trechos, assim como em muitas outras passagens da obra, percebemos um dos usos do autor que não se afasta do uso padrão e que identifica o seu traçar estilístico: o sabor do uso de vírgulas antes do aparecimento do traçar verbal, ora separando o sujeito do verbo por algum traçar atributivo, ora invertendo a posição do atributo adverbial, antecipando-o ao sujeito, à base substancial do acontecimento.

Destaquemos uma das orações destes trechos: "algumas pessoas se curvavam sobre livros, com gestos lentos" - o acontecimento é a leitura, marcada pelo rema 'curvar-se', o substrato pragmático da frase, seu sujeito, está indicado por traços nominal e pronominal, ou, mais propriamente, 'prenominal'; a circunstância primeira é locativa - 'sobre os livros', à 
qual se segue outro traço adverbial, desta vez modal - 'com gestos lentos'. E, assim, o escritor compôs esses excertos com maestria transdutiva saborosa e cheia de saber alagmático.

\section{CONSIDERAÇÕES}

Adentremos nas nossas considerações por meio de um último trecho da obra, em que uma das personagens tinha cochilado na biblioteca, justamente aquele sujeito citado acima, o que tremia na presença de livros: "Acordou com a sensação de que alguém lhe tinha tocado na face, mas era apenas o sol da tarde que lhe aflorava o rosto" (MAGALHÃES, 2011, p. 161).

Mesmo para o que dorme com medo dos livros, é preciso aflorar-lhe o rosto com o calor do afeto na busca de perceptos, de conceitos e de funções - que são, respectivamente, objetos e resultados da arte, da filosofia e da ciência.

É preciso que os professores de língua portuguesa alcancem uma pedagogia que sensibilize bebês na creche, crianças na escola e jovens no colégio e na universidade; é necessário, igualmente, que guerreemos contra os estigmas linguísticos, contra as violências simbólicas, contra as exclusões sociais e culturais, e contra toda forma de preconceito linguístico-gramatical.

Já que gramas são traços ou riscos..., riscar é necessário, assim como o viver! E, já que riscar é preciso e viver não é "preciso", risquemos e vivamos os paradoxos do dizer-se excessivo - do desejo do dizer -, do querer dizer o excesso.

Vivamos bem, contemplando e experimentado o belo e o bom; vivamos as nossas univocidades por meio de novos caminhos: "uma mesma voz para todo o múltiplo de mil vias, um mesmo Oceano para todas as gotas, um só clamor do ser para todos os entes" (DELEUZE, 1968, p. 388). Almejemos, juntamente, o desejo enquanto excesso, com a condição de atingirmos para cada indivíduo e para cada gota e para cada caminho o estado de excesso.

\section{REFERÊNCIAS}

DAMASCENO, V. Notas sobre a individuação extensiva em Simondon e Deleuze. O que nos faz pensar, n. 21, maio 2007. Disponível em: http://oquenosfazpensar.fil.puc-rio.br/import/ pdf_articles/OQNFP_21_11_veronica_dasmasceno.pdf Acesso em:

DELEUZE, G. Crítica e Clínica. São Paulo: Editora 34, 2011.

DELEUZE, G. Cours de Vincennes sur Spinoza, 1978-1981. Disponível em: www.webdeleuze. com Acesso em: mar. 2020.

DELEUZE, G. Différence et Répétition. Paris: Presses Universitaires de France, 1968.

DELEUZE, G. Nietzsche. Lisboa: Edições 70, 2016. 
DELEUZE, G. Nietzsche e a filosofia. São Paulo: n-1 edições, 2018.

DELEUZE, G.; GUATTARI, F. O Anti-Édipo. São Paulo: Editora 34, 2010.

DELEUZE, G.; GUATTARI, F. O que é filosofia? São Paulo: Editora 34, 2016.

FARACO, C. A. Norma culta brasileira: desatando alguns nós. São Paulo: Parábola, 2008.

IAFELICE, H. Deleuze devorador de Spinoza: teoria dos afectos e educação. São Paulo: FAPESP, 2015.

MACKENZIE, A. Transduction: invention, innovation and collective life. 2003. Disponível em: https://www.lancaster.ac.uk/staff/mackenza/papers/transduction.pdf. Acesso em: abr. 2020.

MAGALHÃES, G. Madrugada na tua alma. Lisboa: Alétheia, 2011.

NEVES, J. P. 0 apelo do objeto técnico. Porto: Campo das Letras, 2006.

OLIVEIRA, D. V. A técnica como modo de existência em Gilbert Simondon: tecnicidade, alienação e cultura. Doispontos, Curitiba, São Carlos, v. 12, n. 1, 2015.

OLIVEIRA, L. R. P. F.; DUARTE, L. J. Al.; PEEL, M. A. F. A experimentação das palavras: da imagem-percepção à imagem-relação (da transdução à alagmática). João Pessoa: Ideia, 2019.

OLIVEIRA, L. R. P. F.; COSTA, P. V.; SILVA, R. S. S. Abecê filosófico da arte-cartografia. João Pessoa: Ideia, 2020.

RIBEIRO, Fernando Maia Freire. Pela inocência do pré-individual: pensando com Simondon. Ensaios Filosóficos, v. 1, abr. 2010. Disponível em: http://ensaiosfilosoficos.com.br/Artigos/ Artigo1/Fernando_Maia_Freire_Ribeiro.pdf. Acesso em: abr. 2021

SERRES, Michel. [1985]. Os cinco sentidos. Filosofia dos corpos misturados - I. Tradução: Eloá Jacobina. Rio de Janeiro, Bertrand Brasil, 2001

SPINOZA, B. Ética. Tradução: Tadeu. 3. ed. Belo Horizonte: Autêntica, 2007.

Recebido para publicação em: 18 jun. 2020.

Aceito para publicação em: 3 abr. 2021. 